\title{
Simulating the Energy and Water Fluxes from Two Alkaline Desert Ecosystems over Central Asia
}

\author{
Chang-Qing Jing ${ }^{1,2}$ and Long-Hui $\mathrm{Li}^{2}$ \\ ${ }^{1}$ College of Grassland and Environment Sciences, Xinjiang Agricultural University, Urumqi 830052, China \\ ${ }^{2}$ State Key Laboratory of Desert and Oasis Ecology, Xinjiang Institute of Ecology and Geography, \\ Chinese Academy of Sciences, Urumqi 830011, China \\ Correspondence should be addressed to Long-Hui Li; lhli@ms.xjb.ac.cn
}

Received 15 September 2015; Revised 13 November 2015; Accepted 16 November 2015

Academic Editor: Sergio M. Vicente-Serrano

\begin{abstract}
Copyright (C) 2016 C.-Q. Jing and L.-H. Li. This is an open access article distributed under the Creative Commons Attribution License, which permits unrestricted use, distribution, and reproduction in any medium, provided the original work is properly cited.
\end{abstract}

\begin{abstract}
The Central Asia region is covered by vast desert ecosystems, where the characteristic of energy and water fluxes is different from other humid ecosystems. The application of land surface models (LSMs) in arid and semiarid ecosystems was largely limited. This paper presents a detailed evaluation of Common Land Model (CoLM) at two eddy covariance (EC) sites in alkaline desert ecosystems over Central Asia. Simulations of the net radiation $\left(R_{\text {net }}\right)$, latent heat flux $\left(Q_{1 \mathrm{e}}\right)$, sensible heat flux $\left(Q_{h}\right)$, and soil temperature showed that refined estimate of roughness length $\left(Z_{0 m}\right)$ significantly improved the performance of CoLM in simulating turbulent heat fluxes. $Q_{\mathrm{le}}$ was increased but $Q_{h}$ was decreased, which were in better agreement with the observations from EC system. The results indicated that accurate parameterization of $Z_{0 m}$ is of crucial importance for predicting energy and water fluxes in LSM when applied in Central Asia desert ecosystems. Sensitivity analysis regarding leaf area index (LAI), $Z_{0 m}$, and albedo $(\alpha)$ showed that $R_{\text {net }}$ is very sensitive to $\alpha$ but $Q_{\mathrm{l}}, Q_{h}$, and soil temperature $\left(T_{\text {soil }}\right)$ are sensitively varying with the estimate of $Z_{0 m}$ at the two EC sites over Central Asia.
\end{abstract}

\section{Introduction}

Terrestrial ecosystem is an important part of the earth system as it controls land-atmosphere interactions. Land surface model, which described plant physiological behavior in relation to soil and atmospheric processes, was widely used to quantify the land-atmosphere interactions for improving the predictability of Earth System Models (ESMs) [1-4]. LSM consists of different biogeophysical and biogeochemical processes, which described energy, momentum, water, and $\mathrm{CO}_{2}$ exchange between the atmosphere and the land surface. LSMs became increasingly complicated since Manabe introduced the first bucket model in 1969 [5]. Increases in observations obtained from in situ instruments and satellites provided more opportunities to test, validate, and evaluate the performance of LSMs in specific terrestrial ecosystem [6,7]. Despite the significant improvement of LSMs during the past few decades, large errors and uncertainties still existed [8]. Errors and uncertainties underlying the LSMs can result from model structure, model initial conditions, model parameters, and model forcing data, and evaluating the performance of LSMs among different ecosystems is helpful to identify and diagnose the errors of the model in structure and parameters and hence to reduce the uncertainties [9].

Evaluating LSMs would provide a reliable indicator of performance of models under various climates and among different biomes. Comparing the model results with measurements is a routine approach in the assessment of a particular LSM [10]. Application of LSMs was intensively implemented in humid and dense vegetation regions, but LSM was rarely investigated in dryland or sparse-vegetated areas (e.g., deserts ecosystems in Central Asia) [11, 12]. Absence of the exquisite description on specially ecophysiological characteristics of dryland ecosystems further enlarged the errors of the LSMs in simulating turbulent fluxes $[13,14]$. Under humid areas, LSMs were found to perform well [12]. However, around onethird of the world's area was belonging to dryland ecosystems [15], where the land surface fluxes, such as $Q_{h}, R_{\text {net }}$, and 
TABLE 1: Location, soil, vegetation, climate factors, and flux time series at KZ-Ara site and KZ-Bal site.

\begin{tabular}{lccccccc}
\hline Site & Lon. & Lat. & Soil & Dominant vegetation & Temperature $\left({ }^{\circ} \mathrm{C}\right)$ & Precipitation $(\mathrm{mm})$ & Simulation period \\
\hline KZ-Ara & $61^{\circ} 05^{\prime} \mathrm{E}$ & $45^{\circ} 58^{\prime} \mathrm{N}$ & Alkaline & Shrub & 8.3 & 140.5 & May-Aug. 2012 \\
KZ-Bal & $76^{\circ} 39^{\prime} \mathrm{E}$ & $44^{\circ} 34^{\prime} \mathrm{N}$ & Alkaline & Grass & 5.7 & 140.2 & May-Sep. 2012 \\
\hline
\end{tabular}

ground surface temperature are less dependent on vegetation parameters and soil hydraulic parameters, but more on energy-related soil parameters and surface parameters (surface albedo, the ground surface emissivity, aerodynamic roughness length, and thermal roughness length) [16]. Unfortunately, application of LSMs in arid and semiarid ecosystems was largely limited. For example, recent studies have found that CoLM extremely underpredicted latent heat fluxes in dryland areas $[13,17]$. Prediction errors can be derived from the forcing data, physics processes, and the parameterizations of land characteristic (which mainly included vegetation and soil effects) [2, 18]. Vegetation effects consist of different plant types that differ in leaf areas, root profile, height, optical properties, stomatal conductance, and roughness length. Soil properties can be soil texture (percent of sand and clay) and soil thermal and hydraulic parameters. The errors resulting from parameterizations of these processes will cause large errors for LSMs in modelling the turbulent fluxes.

The Central Asia dryland area is characterized by a typical arid continental climate, complex terrain, sparse vegetation, and high heterogeneity in land surface, which inevitably proposes high challenges on the application of LSMs [19]. Investigating the energy and water exchange between land surface and atmosphere was of great importance to hydrological and ecological research $[15,20]$. Few recent studies have evaluated the performance of the CoLM to reproduce energy and water vapor fluxes in China's desert ecosystem $[13,21]$. They have found that root distribution and root water uptake function have significant effects on the performance of CoLM in estimating energy and water fluxes. However, $\alpha, Z_{0 m}$, and LAI are also expected to significantly impact the performance of LSMs, which largely influence energy budget, thermodynamic resistance, and turbulence fluxes. The errors resulting from these critical parameterizations will cause large error and uncertainties for LSMs in the estimates of sensible and latent heat fluxes. Unfortunately, a comprehensive evaluation of LSMs and their uncertainties caused by $\alpha, Z_{0 m}$, and LAI was never investigated in Central Asia dryland ecosystems.

Therefore, the main objectives of this research are (1) to evaluate the performance of CoLM of two desert ecosystems in Kazakhstan using EC observations during the growing seasons, for the purpose of investigating how well the CoLM is able to simulate the energy and water fluxes over Central Asia land surface, and (2) to analyze model sensitivities to albedo, roughness length, and leaf area index.

\section{Materials and Methods}

2.1. Site Description. Two sets of EC equipment were established in representative dryland ecosystem in Kazakhstan in 2012 (Figure 1). One site is close to Aral Sea and the other is close to Balkhash Lake. The Aral Sea site (KZAra, $61.08^{\circ} \mathrm{E}, 45.96^{\circ} \mathrm{N}$ ) is located northeast of the Aral Sea and at the edge of Aralkum Desert. Within radius of $5 \mathrm{~km}$ of the KZ-Ara site, the dominant plant species are weedgrass and reed vegetation in combination with xerophytic and halophytic desert semishrubs and shrubs. The average fraction of vegetation coverage was about $30 \%$. The dominant soil type was solonchak. Historical climatic records with long term observations showed that mean annual precipitation is $140 \mathrm{~mm}$ and mean annual air temperature is $8.3^{\circ} \mathrm{C}$ (Table 1 ). The Balkhash Lake site (KZ-Bal, $\left.76.63^{\circ} \mathrm{E}, 44.57^{\circ} \mathrm{N}\right)$ is located between the Balkhash Lake and the Kapchagay Reservoir and between original deserts and oasis croplands. Within radius of $5 \mathrm{~km}$ of the $\mathrm{KZ}$-Bal site, the dominant plant species are irrigated crops, grasses, and desert shrubs. The average fraction of vegetation coverage was about $40 \%$. The soil in the KZ-Bal site is saline solonchak [22]. Historical climatic records with long term observations showed that mean annual precipitation is $140 \mathrm{~mm}$ and mean annual air temperature is $5.7^{\circ} \mathrm{C}$ (Table 1 ). For detailed information about the two sites, refer to $\mathrm{Li}$ et al. [23].

2.2. Eddy Covariance and Ancillary Measurements. At each site, a set of EC systems was used to measure energy, water vapor, and $\mathrm{CO}_{2}$ fluxes between the land surface and the atmosphere. The eddy covariance consists of an open path gas analyzer (LI-7500, LICOR) and a three-dimensional sonic anemometer thermometer (Wind Master Pro, Gill Instruments, Lymington, UK). The EC system also measures air temperature and humidity (HMP45C, Campbell), precipitation (TE525MM, Texas Electronics, Dallas, TX, USA), short-wave and long-wave radiation (CNR-1, Kipp \& Zonen, Delft, Netherlands), soil temperature (TCAV, Campbell), soil moisture content (CS616, Campbell Sci.), and soil heat flux (HFP01, Hukseflux, Delft, Netherlands). The open path gas analyzer and the three-dimensional sonic anemometer thermometer are mounted at $2.0 \mathrm{~m}$ above the ground. Soil temperature, soil moisture content, and soil heat flux $(G)$ were measured at 20,40,60, and $80 \mathrm{~cm}$ depth below the ground. Therefore, this study chose the interpolated soil temperature in CoLM on the corresponding depth for comparisons. These data were logged every $30 \mathrm{~min}$ by the data logger at $10 \mathrm{~Hz}$, and all variables were carried out with data processing and gap filling. The data was used for the analysis in this study during growing seasons at the two sites and covered the period from 30 April to 18 August 2012 at the KZ-Ara site and from 23 May to 6 September 2012 at the KZ-Bal site.

2.3. Common Land Model. CoLM [18] is one of the widely used land surface models, which was originally proposed to provide a framework for a truly community developed land 

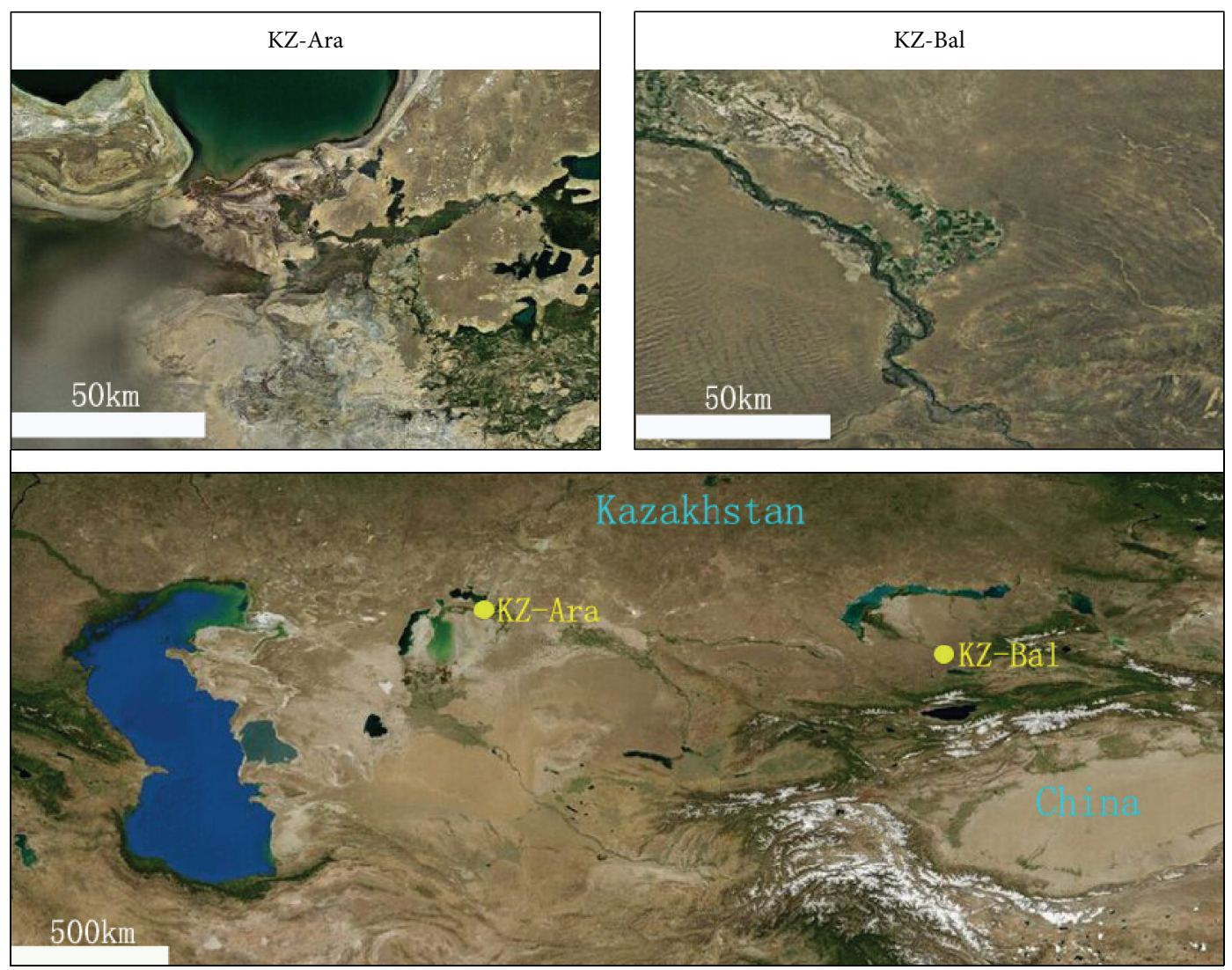

FIGURE 1: Study area and location of the two eddy covariance (EC) sites in Kazakhstan.

component of the National Centre for Atmospheric Research (NCAR) Community Climate System Model (CCSM) [24, 25], and it was subsequently developed by an open collaboration of many scientists. A variety of comprehensive multiyear point observational data over different regions of the world have been used [26-28]. These data were included in the project for the Intercomparison of Land Parameterization Schemes [29], and the results from these extensive tests were useful for CoLM improvement.

CoLM simulates the exchange of energy, mass, and momentum between the atmosphere and terrestrial biosphere through a wide range of ground and canopy biogeophysical processes and allows for the simulation of explicit biophysical mechanisms, including the representation of thermodynamic, hydrologic, and physiological processes [18, 30]. In CoLM, soil temperatures are predicted using a heat diffusion equation in 10 soil layers, and the soil thermal conductivity depends on soil water density. Surface evapotranspiration consists of evaporation of precipitation intercepted by leaves, canopy transpiration, and bare soil evaporation. The sensible heat and water vapor fluxes between the surface and the reference height can be written in the following form:

$$
\begin{gathered}
Q_{h}=-\rho_{a} c_{p} \frac{\left(\theta_{a}-\theta_{s}\right)}{r_{a h}}, \\
E=-\rho_{a} \frac{\left(q_{a}-q_{s}\right)}{r_{a w}},
\end{gathered}
$$

where $Q_{h}$ is sensible heat flux and $E$ is water vapor flux. $\rho_{a}$ is air density and $c_{p}$ is specific heat for dry air $\left(1004.67 \mathrm{~J} \mathrm{~kg}^{-1} \mathrm{~K}^{-1}\right) ; \theta_{a}$ and $\theta_{s}$ are air potential temperature at reference height and surface potential temperature, respectively; $q_{a}$ and $q_{s}$ are water vapor specific humidity at reference height and surface air humidity, respectively. $r_{a h}$ and $r_{a w}$ are the aerodynamic resistances for heat and water vapor, respectively, which are crucial parameters in determining $Q_{h}$ and $E$, calculated by Monin-Obukhov similarity theory [31], and mainly dependent on the thermal roughness length $\left(Z_{0 h}\right)$ and $Z_{0 m}$ [16], as well as the meteorological forcing variables in CoLM, such as air temperature, wind speed, and precipitation.

2.4. Model Simulations and Sensitivity Analysis. The version of CoLM, which integrated an optimal root water uptake function for dryland ecosystem [21], was used (termed S0) in this study. To investigate the effect of roughness length on the performance of CoLM, a simulation driven by an empirical estimate of roughness length (S1) was conducted (Table 2). In S0 simulation, momentum roughness length, thermal roughness length, and the water vapor roughness length $\left(Z_{0 w}\right)$ were all defined the same in CoLM for bare soil $\left(Z_{0 m}=Z_{0 h}=Z_{0 w}=0.05\right)$. However, some research in dryland ecosystems indicated that the abovementioned roughness length values have different magnitude [4, 32-34]. As in the previous studies, Chen et al. [16] found that the 
TABLE 2: The parameterizations of the reference model (S0) and the model with refined roughness length (S1) in CLM at KZ-Ara site and KZ-Bal site. RWUF is an optimal root water uptake function for dryland ecosystem (Jing et al. 2014 [21]), and $W_{c}$, $W_{x}$, and $m$ are empirical constants in RWUF.

\begin{tabular}{|c|c|c|c|c|c|c|c|}
\hline \multirow{2}{*}{ Site } & \multirow{2}{*}{ Simulation } & \multirow{2}{*}{ Land cover type } & \multirow{2}{*}{ Vegetation fraction } & \multirow{2}{*}{$\begin{array}{c}\text { RWUF } \\
\left(W_{c} / W_{x} / m\right)\end{array}$} & \multicolumn{3}{|c|}{ Roughness length for bare soil } \\
\hline & & & & & $Z_{0 m}$ & $Z_{0 h}$ & $Z_{0 w}$ \\
\hline \multirow{2}{*}{ KZ-Ara } & So & Mixed shrub and grassland & $30 \%$ & $(0.8 / 0.5 / 4)$ & $5 E-2$ & $5 E-2$ & $5 E-2$ \\
\hline & S1 & So & So & S0 & $2 E-3$ & $2 E-4$ & $2 E-4$ \\
\hline \multirow[t]{2}{*}{ KZ-Bal } & So & $\begin{array}{l}\text { (1) Irrigated cropland and pasture (35\%) } \\
\text { (2) Herbaceous wetland }(44 \%) \\
\text { (3) Shrub }(21 \%)\end{array}$ & $40 \%$ & $(0.3 / 0.7 / 4)$ & $5 E-2$ & $5 E-2$ & $5 E-2$ \\
\hline & S1 & So & So & So & $2 E-3$ & $2 E-4$ & $2 E-4$ \\
\hline
\end{tabular}

TABLE 3: A baseline of reference exprement (S0) and six different configurations of CLM at each site (S2-S7), as used in this study for sensitivity testing. Two sets of leaf area index (LAI), average roughness length $\left(Z_{0 m}\right)$, and average albedo $(\alpha)$ were used in CLM. " $D$ " refers to the model default parameter setting.

\begin{tabular}{|c|c|c|c|c|c|c|c|}
\hline \multicolumn{4}{|c|}{ KZ-Ara } & \multicolumn{4}{|c|}{ KZ-Bal } \\
\hline Simulation & LAI & $Z_{0 m}$ & $\alpha$ & Simulation & LAI & $Z_{0 m}$ & $\alpha$ \\
\hline S0 & $D$ & $D(0.05)$ & $D$ & S0 & $D$ & $D(0.1)$ & $D$ \\
\hline S2 & $D * 0.7$ & D & $D$ & $\mathrm{~S} 2$ & $D * 0.7$ & $D$ & $D$ \\
\hline S3 & $D * 1.3$ & $D$ & $D$ & S3 & $D * 1.3$ & $D$ & $D$ \\
\hline S4 & D & 0.005 & $D$ & S4 & D & 0.01 & $D$ \\
\hline S5 & $D$ & 0.5 & $D$ & S5 & $D$ & 1 & $D$ \\
\hline S6 & $D$ & $D$ & $D * 0.7$ & S6 & $D$ & $D$ & $D * 0.7$ \\
\hline S7 & $D$ & $D$ & $D * 1.3$ & S7 & $D$ & $D$ & $D * 1.3$ \\
\hline
\end{tabular}

surface flux and temperature have different sensitivities to $Z_{0 h}$ and $Z_{0 m}$ and the sensible heat flux is very sensitive to the parameterization schemes of $Z_{0 h}$ in arid regions [16].

A common method to calculate $Z_{0 m}$ and $Z_{0 h}$ is

$$
\begin{aligned}
& Z_{0 m}=z e^{\left(-k U / u_{*}\right)-\varphi_{m}(z / L)}, \\
& Z_{0 h}=z e^{\left(-k\left(T-T_{s}\right) / T_{s}\right)-\varphi_{h}(z / L)},
\end{aligned}
$$

where $z / L$ is a stability parameter ( $L$ is the Monin-Obukhov length and $z$ is the observational height) and $\varphi_{m}(z / L)$ is the stability function of wind profile and becomes 0 at the neutral condition; $U$ is the average wind speed and $u_{*}$ is the surface friction velocity; $\varphi_{h}(z / L)$ is the stability function of the temperature profile and becomes 0 at the neutral condition, $k$ is von Karman constant and equals 0.4, generally, $T$ is the air temperature, and $T_{s}$ is the surface temperature. The relationship between $Z_{0 m}$ and $Z_{0 h}$ can be described as

$$
\ln \left(\frac{Z_{0 m}}{Z_{0 h}}\right)=k b^{-1}
$$

where $k b^{-1}$ can be obtained from the bulk transfer equation as

$$
k b^{-1}=\frac{k u_{*}\left(T_{s}-T\right)}{H / \rho c_{p}}-\left[\ln \frac{z-d_{0}}{Z_{0 m}}-\varphi_{h}\left(\frac{z}{L}\right)\right],
$$

where $H$ is the observed sensible heat flux, $\rho$ is the air density, $c_{p}$ is the specific heat for dry air, and $d_{0}$ is the zero plane displacement. Thus, the relationship among $Z_{0 m}, Z_{0 h}$, and $Z_{0 w}$ is described as

$$
Z_{0 h}=Z_{0 w}=Z_{0 m} e^{-k b^{-1}},
$$

where the excess resistance to heat transfer $k b^{-1}$ is important to the sensible heat exchange between land surface and atmosphere, and there are linear correlations between $k b^{-1}$ and surface temperature.

$Z_{0 m}$ is physically related to the geometric roughness of surface elements and can be derived from the wind speed and temperature profiles. Bao et al. [4] and Yang et al. [34] argued that this scheme overestimated $Z_{0 h}$ and would misestimate the energy and water fluxes. Momentum transport is more efficient than heat transport, due to the influence of pressure fluctuation, because individual roughness elements may enhance the momentum flux through form drag with little contribution to the area-averaged heat flux [35].

An appropriate method suggested by Zhang et al. [36] was employed to estimate $Z_{0 m}$ at desert ecosystems. In desert, $Z_{0 m}$ was estimated as $0.0019 \pm 0.0071 \mathrm{~m}$ and $Z_{0 h}$ and $Z_{0 w}$ were at same order but almost one magnitude lower than $Z_{0 m}$ [36]. In this study, $Z_{0 m}$ was set as $0.002 \mathrm{~m}$, and $Z_{0 h}=Z_{0 w}=0.0002 \mathrm{~m}$ for bare soil at the two sites (Table 2).

This research further investigated the sensitivities of the CoLM to LAI, $Z_{0 m}$, and $\alpha$. Therefore, other six simulations, by increasing or decreasing the value of each parameter, were conducted. The specifications of all simulations are listed in Table 3. In order to avoid the cross-influence of each parameter, all sensitivity tests took the simulation S0 as a reference. 


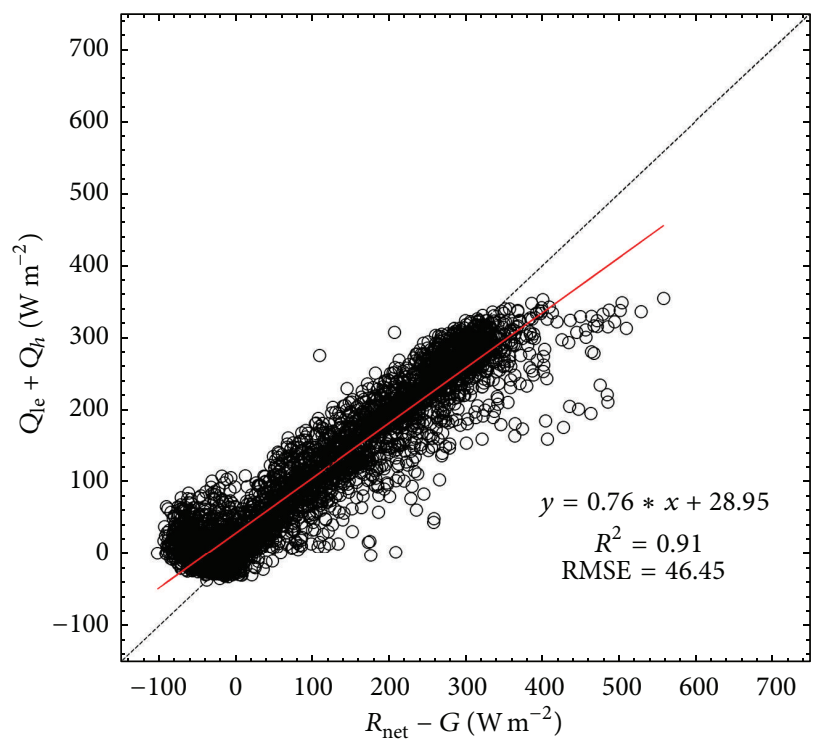

(a) KZ-Ara

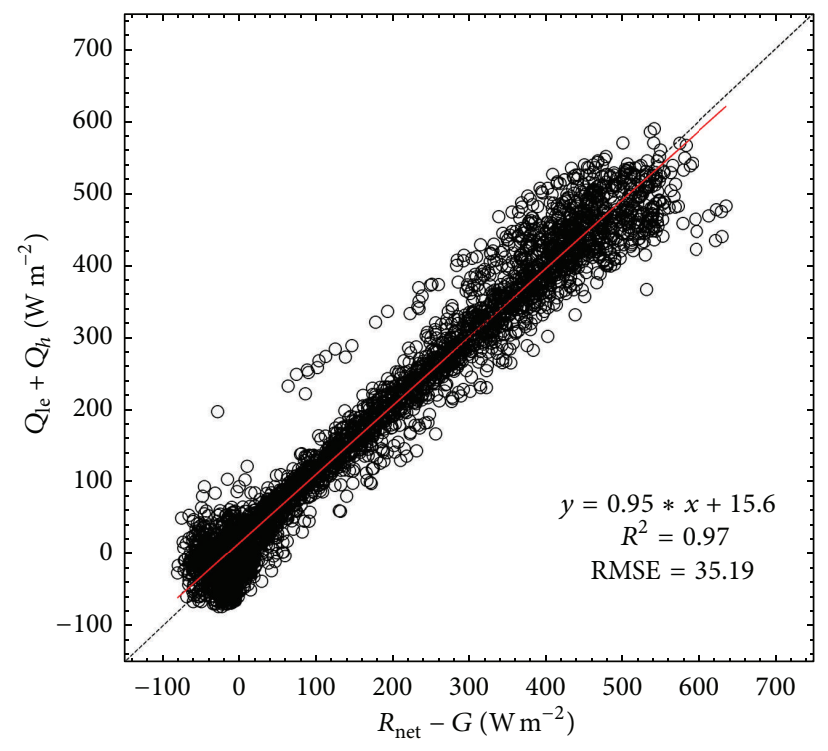

(b) KZ-Bal

FIgURE 2: Energy balance closure at the KZ-Ara site and the KZ-Bal site. The slope of the fitted line represents energy closure ratio and $R^{2}$ is the coefficient of determination. RMSE $\left(\mathrm{W} \mathrm{m}^{-2}\right)$ is the root mean square error. The energy fluxes include sensible heat flux $\left(Q_{h}\right)$, latent heat flux $\left(Q_{\mathrm{le}}\right)$, net radiation $\left(R_{\mathrm{net}}\right)$, and ground heat flux $(G)$.

2.5. Statistical Analysis. Energy balance ratio (EBR) [35] was used to give an overall evaluation of energy balance closure by averaging over random errors in the half-hour measurements at two flux tower sites, and it was calculated by

$$
\mathrm{EBR}=\frac{\sum_{i=1}^{n}\left(Q_{\mathrm{le}}+Q_{h}\right)}{\sum_{i=1}^{n}\left(R_{\text {net }}-G\right)},
$$

where $n$ is the number of half hours of data. The values of EBR close to 1 indicate the best degree of energy balance closure. Additionally, coefficient of determination $\left(R^{2}\right)$, root mean square error (RMSE), slope $\left(b_{s}\right)$, and intercept $\left(b_{0}\right)$ are used to justify the performance of the model.

The Taylor diagram [37] was used to quantify the degree of the sensitivities of the model to management parameters. RMSE, $R^{2}$, and standard error (STD) are used in the Taylor diagram. The output of the model simulation is specified by a single point, with the STD being the polar axis and $R$ the polar angle. The "reference" point represents observations, and the other points refer to the model results from the simulations of sensitivity tests. The distances from the reference point to the other points representing the consequence of the relationship indicate the RMSE. The higher $R$ and the smaller the STD and RMSE, the better the agreement between model and data. When comparing two simulations with different parameter values, the longer the distance between the two simulation points, the greater the sensitivity to that parameter.

\section{Results}

3.1. Energy Balance Closure. The slopes of the linear regression between the observed $Q_{\mathrm{le}}+Q_{h}$ and $R_{\text {net }}-G$ were 0.76 and 0.95 at KZ-Ara and KZ-Bal, respectively. The coefficient of determination $\left(R^{2}\right)$ of the observed $Q_{\text {le }}+Q_{h}$ and $R_{\text {net }}-G$ was 0.91 and 0.97 , and the root mean square error (RMSE) was 46.45 and $35.19 \mathrm{~W} \mathrm{~m}^{-2}$, respectively (Figure 2). Energy balance ratio (EBR) at KZ-Ara and $\mathrm{KZ}$-Bal was 1.11 and 1.06, respectively.

3.2. Modelled $R_{\text {net }}, Q_{l e}, Q_{h}$, and $T_{\text {soil }}$. Figure 3 shows the comparisons between the measurements and the simulations of the reference model (S0) and the model with refined roughness length $(\mathrm{S} 1)$ for $R_{\text {net }}, Q_{\text {le }}$, and $Q_{h}$ at the two Kazakhstan sites. The reference model (S0) significantly underestimated the latent heat flux and overestimated the sensible heat flux at both sites. However, the performance of the refined roughness length (S1) was largely improved in simulating turbulent heat fluxes. The latent heat flux was increased and sensible heat flux was decreased obviously. At the KZ-Ara site, RMSE for $R_{\text {net }}$ decreased from 63.6 to $39.5 \mathrm{~W} \mathrm{~m}^{-2}$. $R^{2}$ values for $Q_{\text {le }}$ given by the two simulations (S0 and S1) were 0.36 and 0.61 , respectively, and RMSE decreased from 41.15 in S0 to $33.3 \mathrm{~W} \mathrm{~m}^{-2}$ in S1 (Table 4). For $Q_{h}$ simulations, the RMSE for S0 was $121.24 \mathrm{~W} \mathrm{~m}^{-2}$, as compared to $58.47 \mathrm{~W} \mathrm{~m}^{-2}$ for $\mathrm{S} 1$ (Table 4 ). The results indicated that the simulation with refined roughness length (S1) significantly improved the performance of the model for both $R_{\text {net }}$ and $Q_{\text {le }}$ and particularly for $Q_{h}$. At the KZ-Bal site, the performance of the simulation with refined roughness (S1) was also greatly improved, $R^{2}$ values for $Q_{\text {le }}$ given by S0 and S1 were 0.9 and 0.92 , respectively, and RMSE decreased from 46.42 in S0 to $43.11 \mathrm{~W} \mathrm{~m}^{-2}$ in S1. $R^{2}$ values for $Q_{h}$ given by the two simulations were 0.7 and 0.67 , respectively, and RMSE decreased from 77.38 in $\mathrm{S} 0$ to $37.97 \mathrm{~W} \mathrm{~m}^{-2}$ in S1 (Table 4, Figure 3). 
TABLE 4: Model performance for simulating $R_{\text {net }}, Q_{\mathrm{le}}$, and $Q_{h}$, indicated by coefficient of determination $\left(R^{2}\right)$, slope $\left(b_{s}\right)$, intercept $\left(b_{0}\right)$, and root mean square error (RMSE, $\mathrm{W} \mathrm{m}^{-2}$ ) of linear regressions between model and observed data at the KZ-Ara site and the KZ-Bal site.

\begin{tabular}{|c|c|c|c|c|c|c|c|c|}
\hline \multirow{2}{*}{ Variables } & \multicolumn{4}{|c|}{ Reference model (S0) } & \multicolumn{4}{|c|}{ Refined roughness length (S1) } \\
\hline & $R^{2}$ & RMSE & $b_{s}$ & $b_{0}$ & $R^{2}$ & RMSE & $b_{s}$ & $b_{0}$ \\
\hline \multicolumn{9}{|c|}{ Site: KZ-Ara } \\
\hline$R_{\text {net }}$ & 0.97 & 63.6 & 1.12 & 28.48 & 0.96 & 39.5 & 0.99 & 7.12 \\
\hline$Q_{\mathrm{le}}$ & 0.36 & 41.15 & 0.74 & 9.66 & 0.61 & 33.3 & 1.02 & 4.67 \\
\hline$Q_{h}$ & 0.89 & 121.24 & 1.86 & 56.6 & 0.86 & 58.47 & 1.06 & 46.93 \\
\hline \multicolumn{9}{|c|}{ Site: KZ-Bal } \\
\hline$R_{\text {net }}$ & 0.98 & 43.86 & 1.04 & 22.7 & 0.98 & 33.07 & 0.96 & 13.9 \\
\hline$Q_{\mathrm{le}}$ & 0.9 & 46.42 & 0.82 & 30.57 & 0.92 & 43.11 & 0.89 & 28.67 \\
\hline$Q_{h}$ & 0.7 & 77.38 & 1.58 & 50.87 & 0.67 & 37.97 & 0.76 & 29.08 \\
\hline
\end{tabular}

To further investigate the effects of refined roughness on the energy fluxes simulations, Figure 4 shows the mean diurnal turbulent fluxes during growing seasons at the two sites. Diurnal variations of the three components of energy fluxes showed typical characteristics at the KZ-Ara site; that is, $R_{\text {net }}>Q_{h}>Q_{\text {le }}$ (Figure 4(a)). The KZ-Bal site is located between oasis croplands and original deserts. Although the amount of the average annual precipitation is similar to KZAra site, the characteristic of the energy fluxes allocation showed higher latent heat flux and lower sensible heat flux compared to the KZ-Ara site (Figure 4(b)). At the KZ-Ara site, S0 overestimated $R_{\text {net }}$ with the peak value of $520 \mathrm{~W} \mathrm{~m}^{-2}$, as compared to the observed peak value $450 \mathrm{~W} \mathrm{~m}^{-2}$. However, the simulation with refined roughness (S1) produced a good agreement for $R_{\text {net }}$ between the simulation and the measurements. In addition, S0 overestimated $Q_{h}$ with the peak value of $400 \mathrm{~W} \mathrm{~m}^{-2}$ at noontime, as compared to $200 \mathrm{~W} \mathrm{~m}^{-2}$ for the measurements. S1 improved the simulation for $Q_{h}$ as well. At KZ-Bal site, both S0 and S1 agreed better with observations for $R_{\text {net }}$ and $Q_{\text {le }}$. S0 significantly overestimated $Q_{h}$ at the daytime. However, the simulation with refined roughness (S1) produced better agreement with the observations.

Figure 5 showed the comparisons of soil temperature between the observation and the simulations of the reference model (S0) and the model with refined roughness length (S1) at each site. Although there are significant challenges when it comes to validating soil temperature from LSM because of the high sensitivities of simulated and measured soil temperature to soil texture, moisture conditions, and the limitations of the measurement, the results from the reference model (S0) and the model with refined roughness length (S1) appeared to be realistic and generally captured the seasonal variation for soil temperature. It was found that the modelled $T_{\text {soil }}$ in May was underestimated, and significantly improved in June and July, but overestimated in August. However, S1 produced higher values of soil temperature than S0. Additionally, the CoLM simulated a smaller vertical soil temperature gradient as shown that the contour for the simulations was more sparse compared with the observation.

3.3. Sensitivity of CoLM to LAI, $Z_{0 m}$, and $\alpha$. In order to investigate the sensitivities of CoLM, the values of the parameters were adjusted in large ranges. Key parameters consist of LAI, $Z_{0 m}$, and $\alpha$ with regard to the simulation of $R_{\text {net }}, Q_{\text {le }}, Q_{h}$, and $T_{\text {soil }}$ at the two EC sites. A reference model (S0) and six independent sensitivity tests (S2-S7, see Table 3) were conducted at each site. This research only chose the modelled soil temperatures at the depth of $20 \mathrm{~cm}$ for sensitivity tests in this study.

The modelled $Q_{\mathrm{le}}$ and $Q_{h}$ in CoLM were divided into two parts, the fluxes on vegetation leaves and the fluxes on the ground. Thus, $Q_{\mathrm{le}}$ showed a more complicated sensitivity to LAI. Since the leaf temperature increased and ground temperature decreased with the increase in LAI, the evapotranspiration from the leaves improved and the ground evaporation weakened, but the total latent heat flux was increased and exhibited a strong sensitivity for $Q_{\text {le }}$ at $K Z$ Ara. When it came to $\mathrm{KZ}$-Bal, the vegetation coverage was larger than KZ-Ara, while continuing to increase LAI has slightly further improved the performance of $Q_{l e}$. Similarly, $Q_{h}$ and $T_{\text {soil }}$ showed a strong sensitivity to LAI. The more the vegetation, the more the solar radiation intercepted. When it came to $Z_{0 m}$, the values of $R_{\text {net }}$ and $Q_{h}$ were increased but $Q_{\text {le }}$ and $T_{\text {soil }}$ were decreased with the increase in $Z_{0 m}$. Figure 6 indicated that $Q_{\mathrm{le}}, Q_{h}$, and $T_{\text {soil }}$ were highly sensitive to $Z_{0 m}$. Taking the KZ-Ara site as an example, $R^{2}$ values for the modelled $Q_{\text {le }}$ improved from 0.4 to 0.7 when $Z_{0 m}$ decreased from 0.5 (S4) to 0.005 (S5). Figure 6 also showed a strong sensitivity of albedo to $R_{\text {net }}, Q_{h}$, and $T_{\text {soil }}$. The imprecise settings of albedo may enlarge the errors for sensible heat flux in CoLM. Ground sensible heat flux was negatively correlated to albedo. The increase in the surface albedo decreased the solar radiation absorbed by soil, and soil temperature was decreased. However, $Q_{\text {le }}$ was slightly sensitive to albedo (Figure 6).

These sensitivity analysis results demonstrated that the improvement in model performance observed in S2-S7 was significantly affected by the values of these three parameters in CoLM, further justifying the significance of these key parameters (LAI, $Z_{0 m}$, and albedo) to the Common Land Model.

\section{Discussion}

Arid and semiarid areas cover approximately one-third of the global terrestrial land surfaces [15]. Central Asia has 


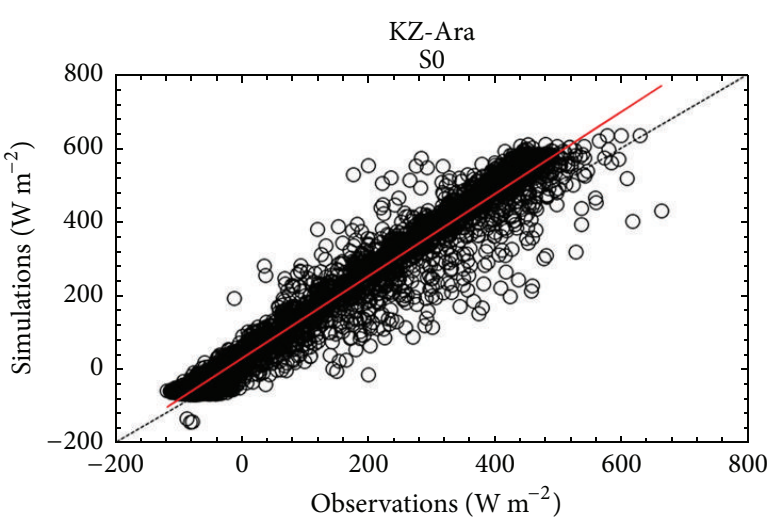

(a) $R_{\text {net }}$

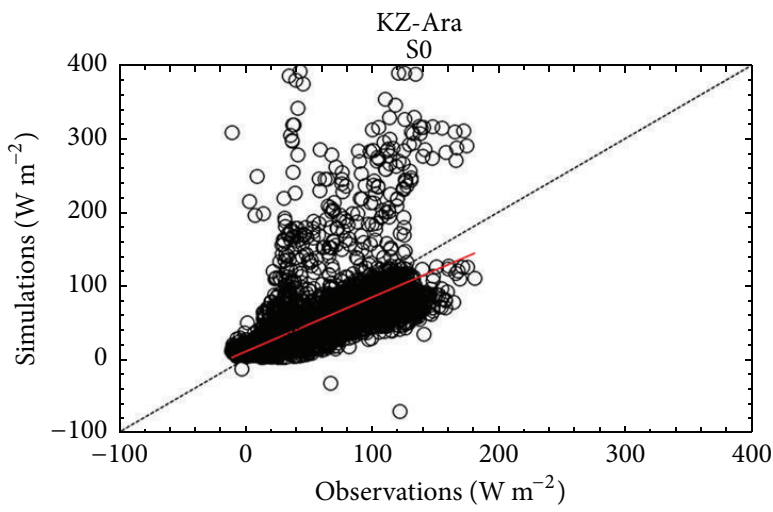

(c) $Q_{\mathrm{le}}$

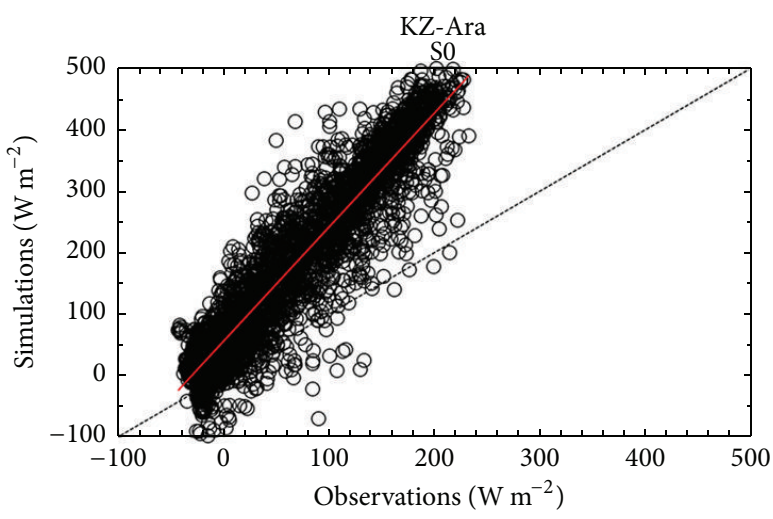

(e) $Q_{h}$

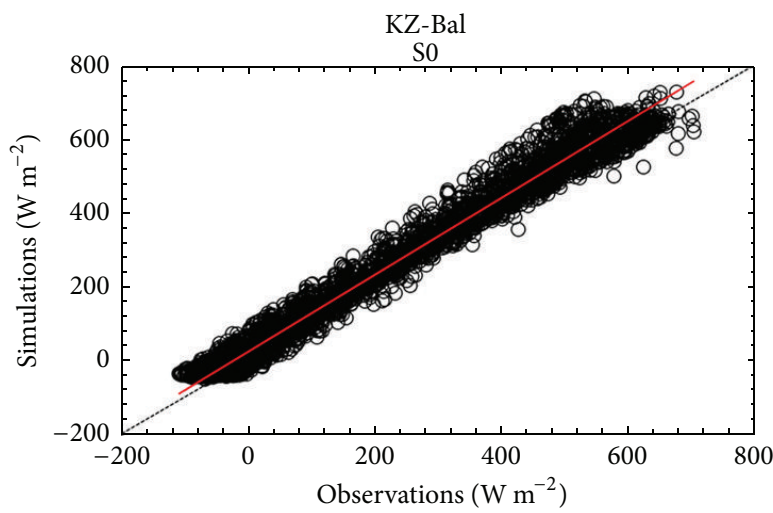

(g) $R_{\text {net }}$

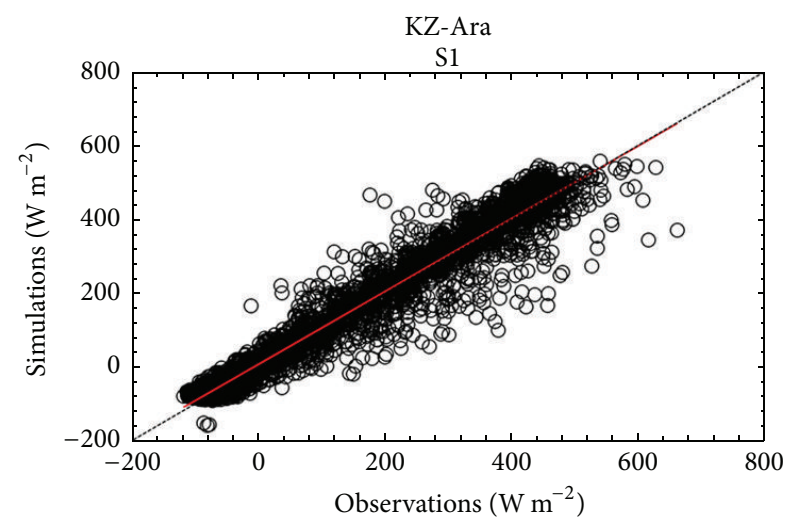

(b) $R_{\text {net }}$

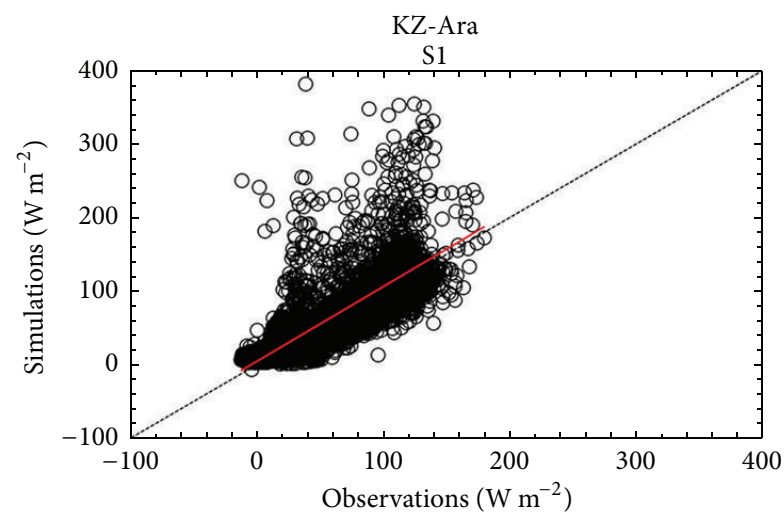

(d) $Q_{\text {le }}$

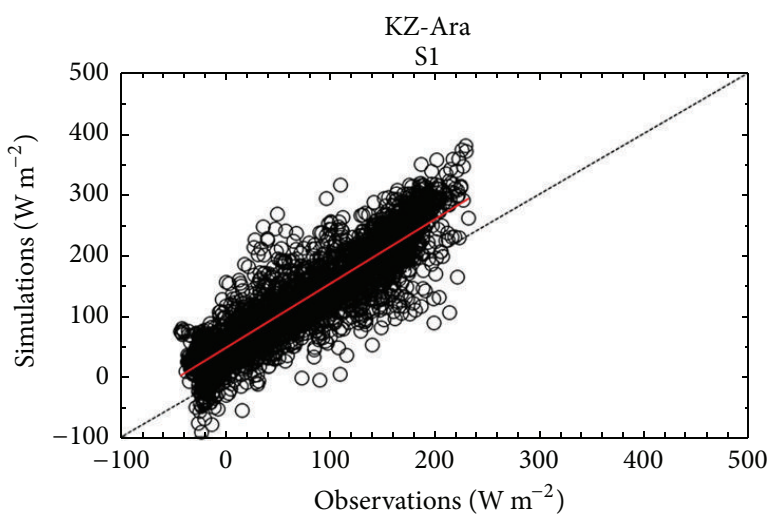

(f) $Q_{h}$

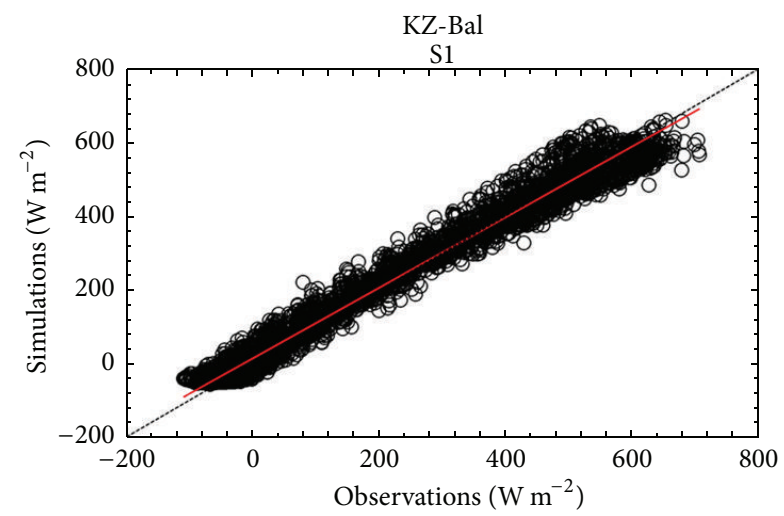

(h) $R_{\text {net }}$

Figure 3: Continued. 


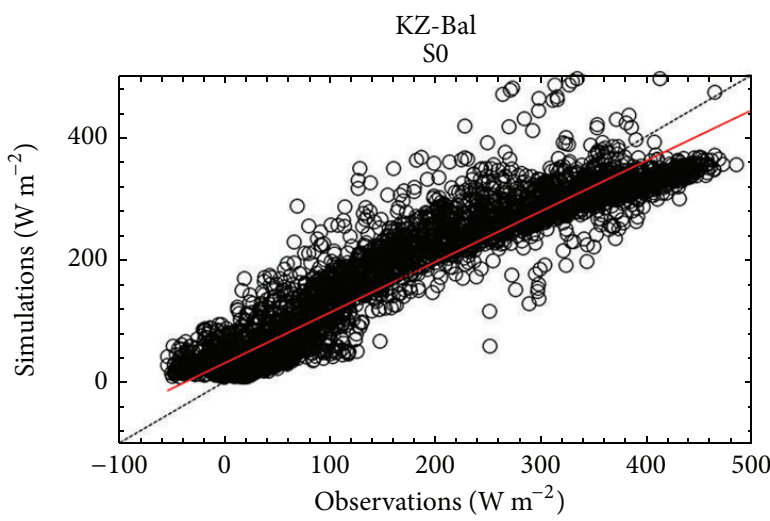

(i) $Q_{\text {le }}$

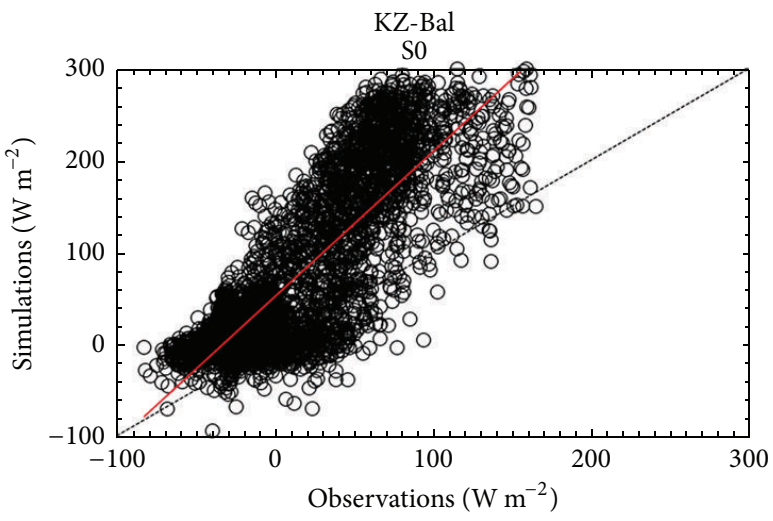

(k) $Q_{h}$

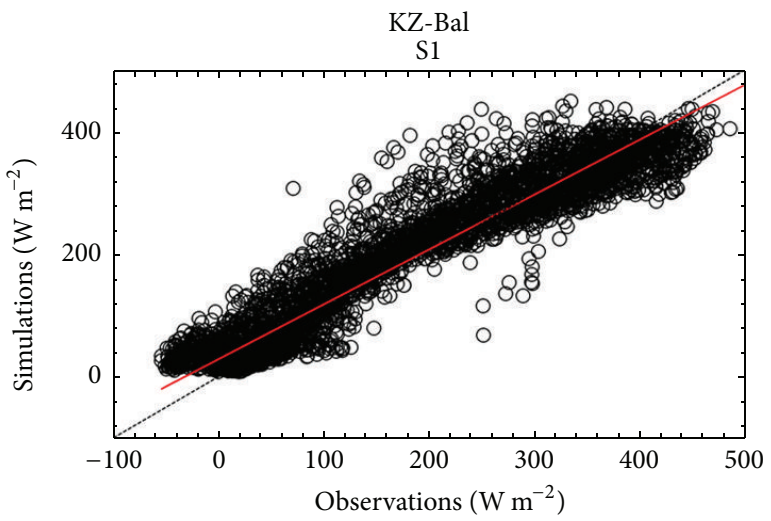

(j) $Q_{\mathrm{le}}$

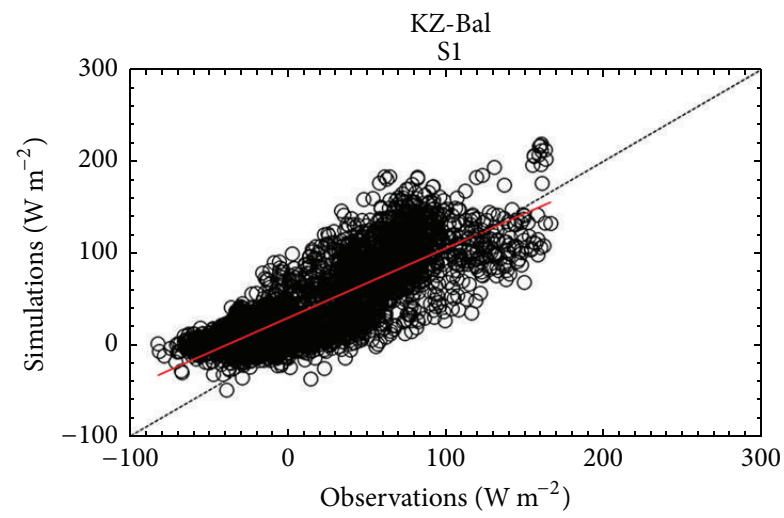

(l) $Q_{h}$

FIGURE 3: Comparison between the measured half-hourly net radiation $\left(R_{\text {net }}\right)$, latent heat flux $\left(Q_{\text {le }}\right)$, and sensible heat flux $\left(Q_{h}\right)$ and the values simulated by the reference model (S0) and the model with refined roughness length (S1) at the KZ-Ara and KZ-Bal sites. The solid red line represents the linear regression between the simulation and the observed data, and the dashed line represents a 1:1 relationship between the datasets.

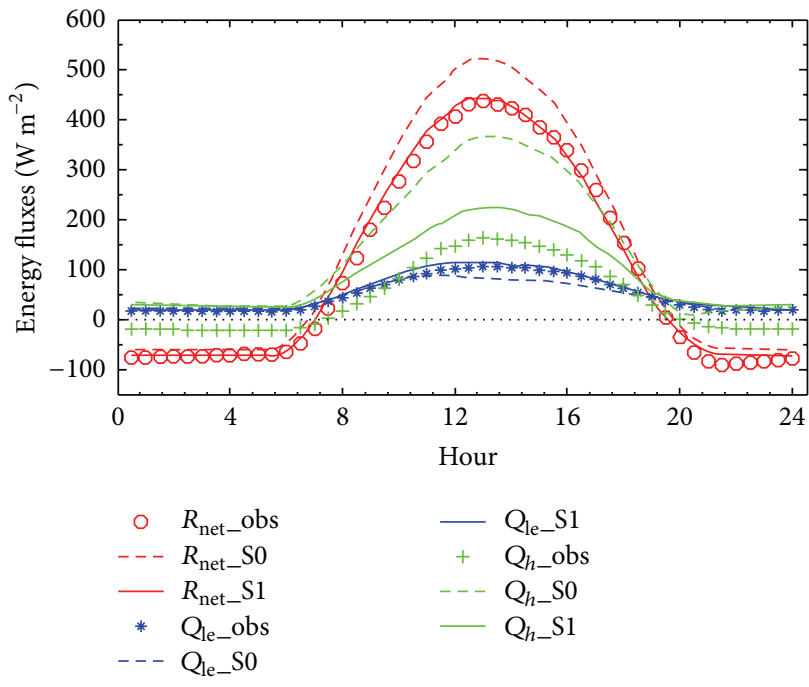

(a) KZ-Ara

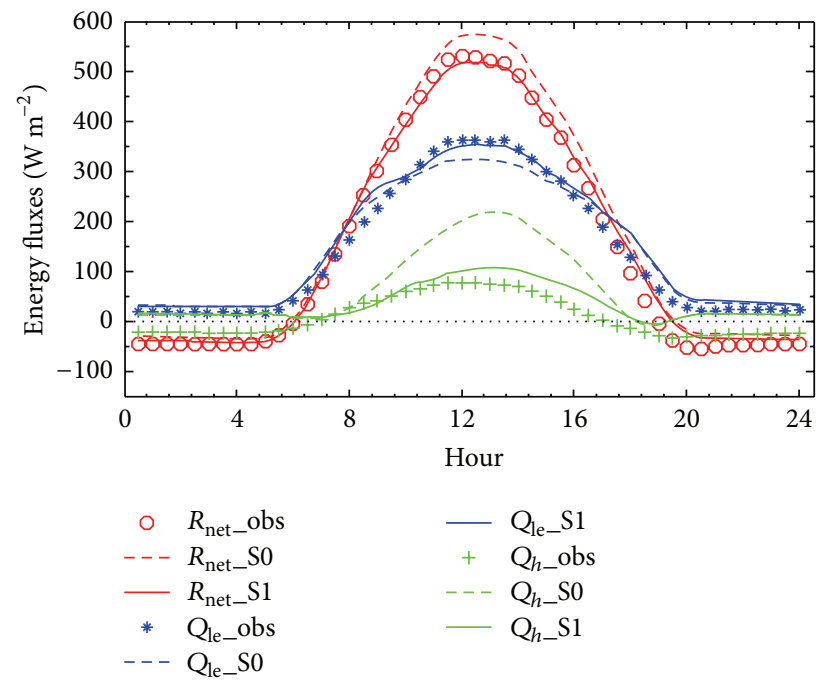

(b) KZ-Bal

FIGURE 4: Comparison between the measured net radiation $\left(R_{\text {net }}\right)$, latent heat flux $\left(Q_{\mathrm{le}}\right)$, and sensible heat flux $\left(Q_{h}\right)$ and the values simulated by the reference model (SO) and the model with refined roughness length (S1) on a diurnal course at the KZ-Ara and KZ-Bal sites. The diurnal flux values were calculated as the mean values of all data at same measurement time in a day for the entire time period. 


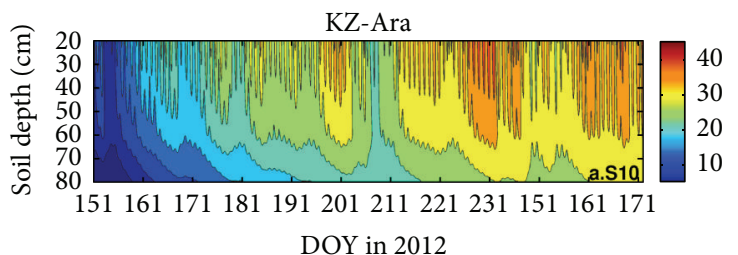

(a)

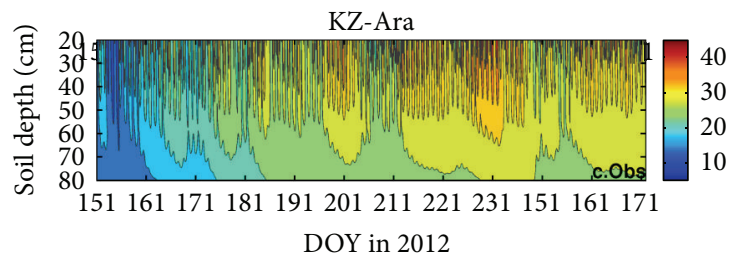

(c)

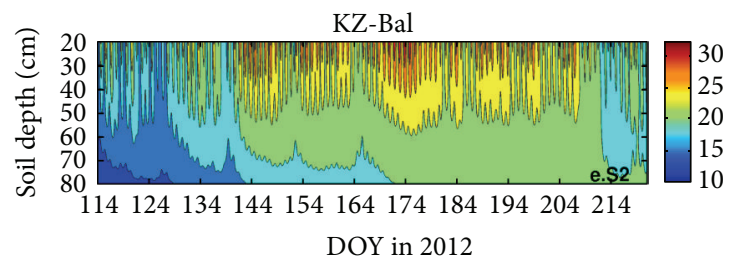

(e)

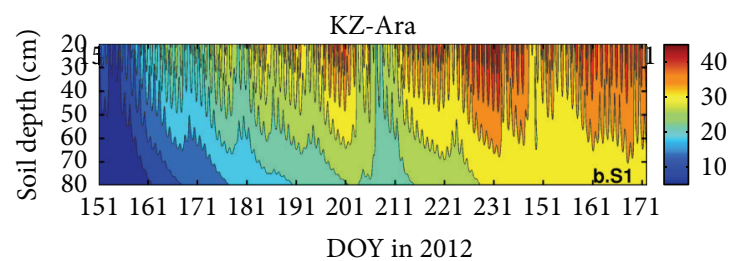

(b)

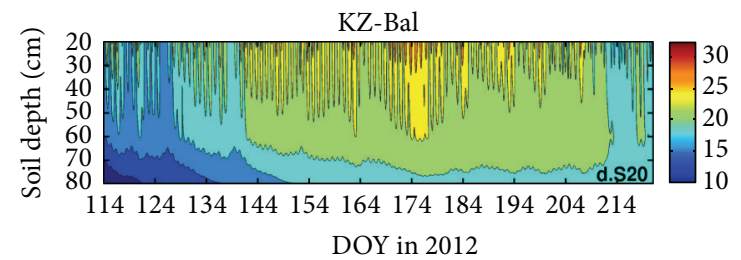

(d)

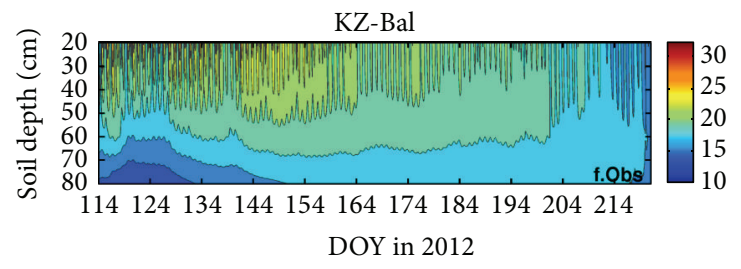

(f)

Figure 5: Panels (a) and (b) are the isograms changed with time and depth variation for the reference model (S0) and the model with refined roughness length (S1), and (c) shows the corresponding observed data at the depth of 20-80 cm below ground at the KZ-Ara site; panels (d) and (e) are the isograms for S0 and S1 and (f) shows the observations at the KZ-Bal site.

vast proportion of dryland ecosystems, where climate was featured as hot and dry during growing season [19] and the vegetation is sparse. The characteristic of dryland ecosystems is significantly different from those in humid areas in terms of surface energy budget. Many researchers have focused on ecosystem functioning and structure in response to climate change. Kariyeva et al. [38] examined spatiotemporal change patterns and interactions between terrestrial phenology and climate change in Central Asia during the period 1981-2008. Lioubimtseva et al. [19] have found that local and regional human impacts in arid zones can significantly modify land surface albedo, as well as water exchange and nutrient cycles that could have essential impacts on the climate at both the regional and global scales. Such kind of analyses advanced our understanding on the response of dryland ecosystem behaviour and functioning to climate change. However, applying LSM into dryland ecosystems was far more limited. Recently, the CoLM has been validated at one desert shrub ecosystem in Xinjiang, China, and the results found that root fraction and root water uptake have important effects on the performance of CoLM in simulating energy and water fluxes $[13,21]$. In this study, a refined parameterization of CoLM has been evaluated at two newly built EC sites in Kazakhstan.

The most commonly used technique to obtain land surface turbulent fluxes is measurement of eddy covariance system, and the analyzer was based on flux footprint models. The footprint concept is the probability that a scalar coming from a given elemental source reaches the measurement point. Footprint models describe the relationship between the spatial distribution of surface sources and the measured signal using footprint functions. Several flux footprint models have been designed [39-42]. But most of them cannot account for inhomogeneous turbulence or require larger computational resources. Göckede et al. [43] improved an Eulerian footprint model use of satellite maps for explicit assignment of surface type. Göckede et al. [44] and Rebmann et al. [45] applied this new model at the EC sites and obtained satisfactory results. At present, footprint models are used to estimate the source areas contributing to the flux observations. In addition, they provide a tool for quality control of the flux measurements and provide guidance in designing experiments [46]. Thus, the footprint models have considerable potential in microclimatology investigations, especially in studies which include nonhomogeneous surfaces.

The momentum roughness length $\left(Z_{0 m}\right)$, thermal roughness length $\left(Z_{0 h}\right)$, and the water vapor roughness length $\left(Z_{0 w}\right)$ are crucial parameters for calculating momentum and heat fluxes in bulk transfer equations, which is one of the essential components in LSMs. It has been widely observed that $Z_{0 m}$ differs from $Z_{0 h}$ and $Z_{0 w}$ [4, 47]. Unfortunately, $Z_{0 m}, Z_{0 h}$, and $Z_{0 w}$, up to date, are still treated as constants in most LSMs. Inaccurate estimates of roughness length would enlarge the bias of simulated energy and water fluxes in LSMs. Many researchers have found that roughness length strongly depended on surface heterogeneity, vegetation height, and coverage $[48,49]$. Therefore, the values of roughness length vary considerably in different geographical context or vegetation types [50-54]. Dryland ecosystems were sparsely 
KZ-Ara

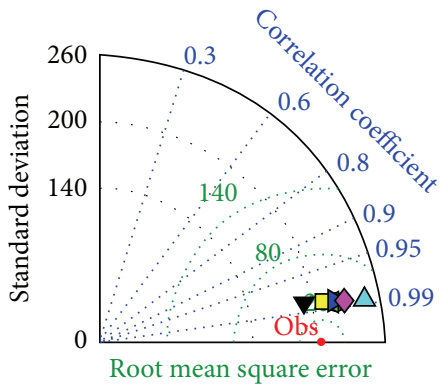

(a)

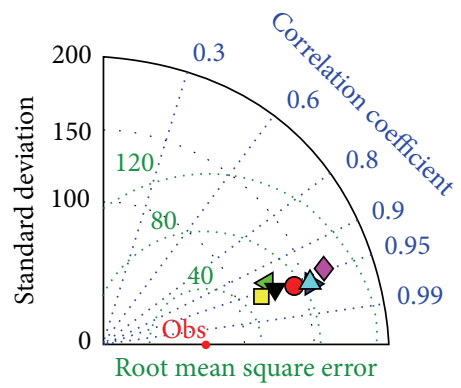

(c)

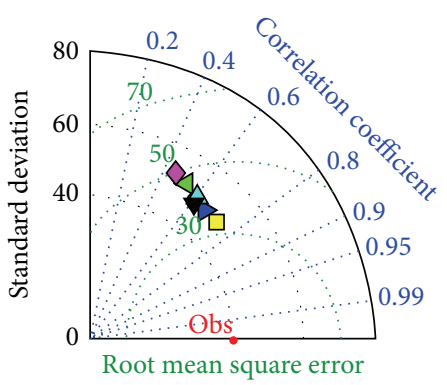

(b)

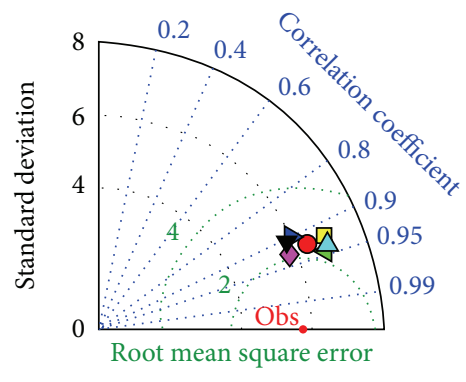

(d)

KZ-Bal

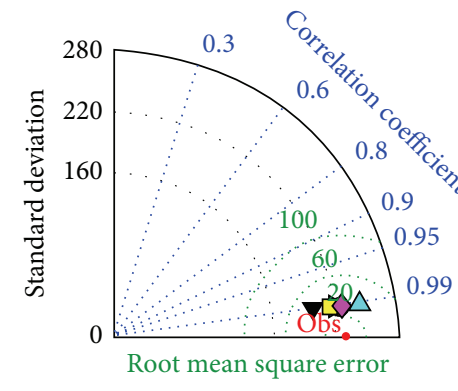

(a)

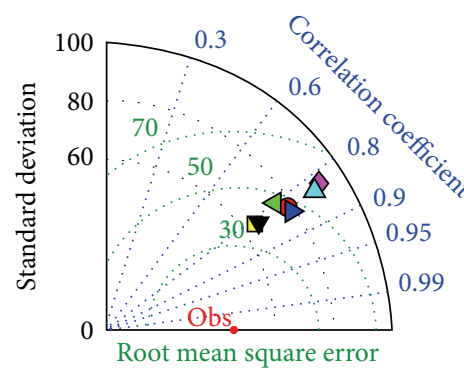

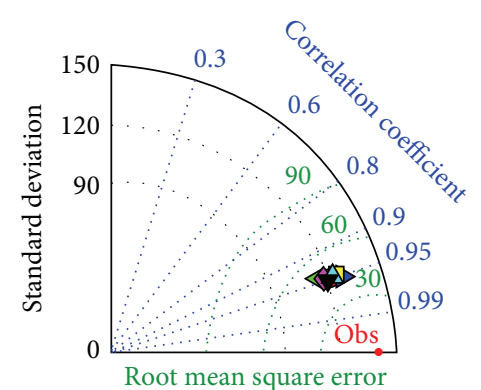

(b)

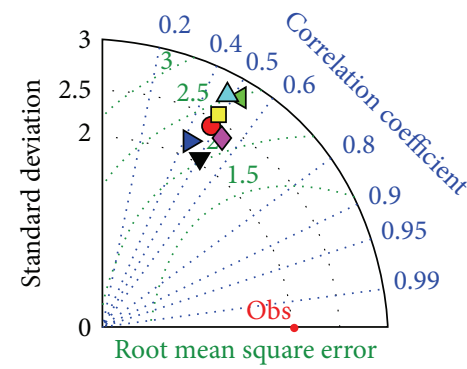

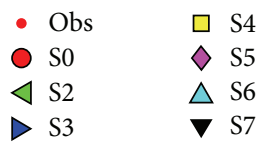

(d)

(c)

FIGURE 6: Taylor diagram plot of the simulated $R_{\text {net }}(\mathrm{a}), \mathrm{Q}_{\mathrm{le}}(\mathrm{b}), \mathrm{Q}_{h}(\mathrm{c})$, and $T_{\text {soil }}(\mathrm{d})$ computed from a reference model (S0) and six independent sensitivity tests (S2-S7, see Table 3) from the CoLM against EC observations at the two EC sites. Standard deviation (STD, W m ${ }^{-2}$ ) is calculated as the simulated variables divided by the observed data. "Obs" refers to observed data points. Root mean square error (RMSE, $\mathrm{W} \mathrm{\textrm {m } ^ { - 2 }}$ ) is represented by green lines. $R$ is the correlation coefficient. The higher the $R$ and the smaller the STD and RMSE, the better the agreement between model and data. When comparing two simulations with different parameter values, the longer the distance between the two simulation points, the greater the sensitivity to that parameter. 
vegetated, with vegetation fraction of $10 \%-40 \%$ at Central Asia desert ecosystems. Bare soil has larger proportion in the Central Asia desert ecosystems, and its characteristic is entirely different from the high-vegetated land surface, particularly for the roughness length. The values of roughness length were replaced by empirical formula based on experimental observations in this study, and the results found that such treatment significantly improved the performance of the model. The simulated turbulent heat fluxes with default roughness length showed very large variability during a day, especially at daytime. The most possible reason is that the roughness length was extremely overestimated and hence aerodynamic resistance was overestimated in the default version of CoLM. As a consequence, the turbulent exchange was strong and of high fluctuations. However, observed diurnal dynamics of energy fluxes are quite harmonious. Using an empirical approach to estimate roughness length into CoLM significantly improved the performance in simulating turbulent heat fluxes, which indicated that accurate parameterization of roughness length is of crucial importance for predicting energy and water fluxes in LSM when applied in Central Asia desert ecosystems.

Many researches have indicated that LSMs are very sensitive to model physics, land characteristics (including leaf area index, roughness length, albedo, and soil properties), and forcing $[9,29,55,56]$. In Central Asia dryland ecosystems, leaf area index, albedo, and roughness length should be much more important, due to low fraction of vegetation and high heterogeneity of the land surface. Compared with recent findings at a Chinese desert shrub ecosystem [21], which is quite similar to the two sites used in this study, that simulation of latent heat flux in CoLM was strongly dependent on the choice of different root water uptake functions [21]. Land surface and vegetation parameters such as albedo, roughness length, and LAI also showed significant sensitivities in simulating the energy and water fluxes in Central Asia dryland ecosystems. These researches implied that CoLM can be very sensitive to both belowground ecological process (such as root water uptake) and aboveground soil and vegetation properties (LAI, $Z_{0 m}$, and $\alpha$ ) in Central Asia regions, which is different from the sensitivities of LSMs in humid regions $[8,26,57]$.

Vegetation and soil parameters, such as leaf area index, roughness length, and albedo, are closely related to vegetation coverage on the land surface. With recent findings at a Chinese desert shrub ecosystem [21], root water uptake process is more relevant to root distribution and root water uptake efficiency. However, many of these crucial parameters are difficult to observe in large areas. Biases in land surface forcing data and parameterizations in representing soil moisture, soil temperature, and other variables in numerical weather forecast and climate models will enlarge the model errors of water and energy fluxes. Reinitialization of land surface states would mollify this problem if the land surface variables and parameters were reliable and available in large areas and with high spatial resolution. Fortunately, the improvement of remote sensing technologies made these operable. Remote sensing technologies also could obtain LAI, canopy and ground albedo, vegetation height, and other parameters in large regions. To make best use of the satellite-based and ground-based observational data in land surface modelling for investigating global climate change issue in regional area, many land data assimilation systems have been developed $[58,59]$. Such treatment is to generate optimal fields for parameterizing and forcing LSMs [59]. Broad use of land data assimilation systems' results is valuable for predicting climate change, weather, and biological and agricultural productivity and for performing a wide array of studies in the broader biogeosciences.

\section{Conclusions}

In this study, the CoLM, for the first time, has been evaluated at two Central Asia desert ecosystems. Additionally, sensitivities of the model to LAI, $Z_{0 m}$, and $\alpha$ were conducted. Evaluation of the CoLM and their sensitivities against the observed energy fluxes using eddy covariance system and the sensitivity tests resulted in the following conclusions:

(1) The reference simulations (S0) significantly underestimated the latent heat flux and overestimated the sensible heat flux at two sites, especially at KZ-Ara. However, refined estimate of roughness length (S1) significantly improved the performance in simulating turbulent heat fluxes. The latent heat flux was increased but sensible heat flux was decreased, which were in better agreement with the observations from eddy covariance system.

(2) Sensitivity analysis regarding leaf area index, roughness length, and albedo showed that net radiation is very sensitive to albedo but latent and sensible heat fluxes and soil temperature are sensitively varying with the estimate of $Z_{0 m}$ at two EC sites over Central Asia.

\section{Conflict of Interests}

The authors declare that there is no conflict of interests regarding the publication of this paper.

\section{Acknowledgments}

This research was supported by the National Natural Science Foundation of China (Grant no. 41561021) and NSFC-XJ project (Grant no. U1403382).

\section{References}

[1] J. Williams, R. G. Barry, and W. M. Washington, "Simulation of the atmospheric circulation using the NCAR global circulation model with ice age boundary conditions," Journal of Applied Meteorology, vol. 13, no. 3, pp. 305-317, 1974.

[2] G. B. Bonan, "Land surface model (LSM version 1.0) for ecological, hydrological, and atmospheric studies: technical description and users guide," Technical Note PB-97-131494/XAB; NCAR/TN-417-STR, Climate and Global Dynamics Division, National Center for Atmospheric Research, Boulder, Colo, USA, 1996. 
[3] A. J. Pitman, "The evolution of, and revolution in, land surface schemes designed for climate models," International Journal of Climatology, vol. 23, no. 5, pp. 479-510, 2003.

[4] Y. Bao, H. Zuo, S. Lv, and Y. Zhang, "The effect of improved land surface process parameters in Arid area on climatic simulation in GCM," Plateau Meteorology, vol. 23, no. 2, pp. 220-227, 2004.

[5] S. Manabe, "Climate and the ocean circulation: I. The atmospheric circulation and the hydrology of the Earth's surface," Monthly Weather Review, vol. 97, no. 11, pp. 739-774, 1969.

[6] F. M. Schurr, O. Bossdorf, S. J. Milton, and J. Schumacher, "Spatial pattern formation in semi-arid shrubland: a priori predicted versus observed pattern characteristics," Plant Ecology, vol. 173, no. 2, pp. 271-282, 2004.

[7] M. Williams, A. D. Richardson, M. Reichstein et al., "Improving land surface models with FLUXNET data," Biogeosciences, vol. 6, no. 7, pp. 1341-1359, 2009.

[8] G. Abramowitz, R. Leuning, M. Clark, and A. Pitman, "Evaluating the performance of land surface models," Journal of Climate, vol. 21, no. 21, pp. 5468-5481, 2008.

[9] M. Choi, S. O. Lee, and H. Kwon, "Understanding of the common land model performance for water and energy fluxes in a farmland during the growing season in Korea," Hydrological Processes, vol. 24, no. 8, pp. 1063-1071, 2010.

[10] M. L. Goulden, J. W. Munger, S.-M. Fan, B. C. Daube, and S. C. Wofsy, "Measurements of carbon sequestration by long-term eddy covariance: methods and a critical evaluation of accuracy," Global Change Biology, vol. 2, no. 3, pp. 169-182, 1996.

[11] J. Mao, L. Dan, B. Wang, and Y. Dai, "Simulation and evaluation of terrestrial ecosystem NPP with M-SDGVM over continental China," Advances in Atmospheric Sciences, vol. 27, no. 2, pp. 427442, 2010.

[12] T. W. Hudiburg, B. E. Law, and P. E. Thornton, "Evaluation and improvement of the Community Land Model (CLM4) in Oregon forests," Biogeosciences, vol. 10, no. 1, pp. 453-470, 2013.

[13] L. Li, C. van der Tol, X. Chen et al., "Representing the root water uptake process in the Common Land Model for better simulating the energy and water vapour fluxes in a Central Asian desert ecosystem," Journal of Hydrology, vol. 502, pp. 145155, 2013.

[14] L. Li, Y. Wang, Q. Yu et al., "Improving the responses of the Australian community land surface model (CABLE) to seasonal drought," Journal of Geophysical Research G: Biogeosciences, vol. 117, no. 4, 2012.

[15] R. Lal, "Carbon sequestration in dryland ecosystems," Environmental Management, vol. 33, no. 4, pp. 528-544, 2004.

[16] Y. Chen, K. Yang, D. Zhou, J. Qin, and X. Guo, "Improving the noah land surface model in arid regions with an appropriate parameterization of the thermal roughness length," Journal of Hydrometeorology, vol. 11, no. 4, pp. 995-1006, 2010.

[17] X. Zeng, X. Zeng, and M. Barlage, "Growing temperate shrubs over arid and semiarid regions in the Community Land ModelDynamic Global Vegetation Model," Global Biogeochemical Cycles, vol. 22, no. 3, p. 3003, 2008.

[18] Y. Dai, X. Zeng, R. E. Dickinson et al., "The common land model," Bulletin of the American Meteorological Society, vol. 84, no. 8, pp. 1013-1023, 2003.

[19] E. Lioubimtseva, R. Cole, J. M. Adams, and G. Kapustin, "Impacts of climate and land-cover changes in arid lands of Central Asia," Journal of Arid Environments, vol. 62, no. 2, pp. 285-308, 2005.
[20] L. Li, G. Luo, X. Chen et al., "Modelling evapotranspiration in a Central Asian desert ecosystem," Ecological Modelling, vol. 222, no. 20-22, pp. 3680-3691, 2011.

[21] C.-Q. Jing, L. Li, X. Chen, and G.-P. Luo, "Comparison of root water uptake functions to simulate surface energy fluxes within a deep-rooted desert shrub ecosystem," Hydrological Processes, vol. 28, no. 21, pp. 5436-5449, 2014.

[22] V. M. Starodubtsev and S. R. Truskavetskiy, "Desertification processes in the Ili River delta under anthropogenic pressure," Water Resources, vol. 38, no. 2, pp. 253-256, 2011.

[23] L. Li, X. Chen, C. van der Tol, G. Luo, and Z. Su, "Growing season net ecosystem $\mathrm{CO}_{2}$ exchange of two desert ecosystems with alkaline soils in Kazakhstan," Ecology and Evolution, vol. 4, no. 1, pp. 14-26, 2014.

[24] J. T. Kiehl, J. J. Hack, G. B. Bonan, B. A. Boville, D. L. Williamson, and P. J. Rasch, "The national center for atmospheric research community climate model: CCM3*," Journal of Climate, vol. 11, no. 6, pp. 1131-1149, 1998.

[25] W. J. Riley, Z. M. Subin, D. M. Lawrence et al., "Barriers to predicting changes in global terrestrial methane fluxes: analyses using CLM4Me, a methane biogeochemistry model integrated in CESM," Biogeosciences, vol. 8, no. 7, pp. 1925-1953, 2011.

[26] S. Bachner, A. Kapala, and C. Simmer, "Evaluation of daily precipitation characteristics in the CLM and their sensitivity to parameterizations," Meteorologische Zeitschrift, vol. 17, no. 4, pp. 407-419, 2008.

[27] K. W. Oleson, G. Y. Niu, Z. L. Yang et al., "Improvements to the community land model and their impact on the hydrological cycle," Journal of Geophysical Research, vol. 113, no. 1, 2008.

[28] G. B. Bonan, P. J. Lawrence, K. W. Oleson et al., "Improving canopy processes in the Community Land Model version 4 (CLM4) using global flux fields empirically inferred from FLUXNET data," Journal of Geophysical Research, vol.116, article G2, 2011.

[29] A. Henderson-Sellers, Z.-L. Yang, and R. E. Dickinson, "The project for intercomparison of land surface parameterisation schemes," Bulletin of the American Meteorological Society, vol. 74, no. 7, pp. 1335-1349, 1993.

[30] X. Zeng, M. Shajkh, Y. Dai, R. E. Dickinson, and R. Myneni, "Coupling of the common land model to the NCAR community climate model," Journal of Climate, vol. 15, no. 14, pp. 1832-1854, 2002.

[31] T. Foken, "50 years of the Monin-Obukhov similarity theory," Boundary-Layer Meteorology, vol. 119, no. 3, pp. 431-447, 2006.

[32] X. Zeng and R. E. Dickinson, "Effect of surface sublayer on surface skin temperature and fluxes," Journal of Climate, vol. 11, no. 4, pp. 537-550, 1998.

[33] M. Kanda, M. Kanega, T. Kawai, R. Moriwaki, and H. Sugawara, "Roughness lengths for momentum and heat derived from outdoor urban scale models," Journal of Applied Meteorology \& Climatology, vol. 46, no. 7, pp. 1067-1079, 2007.

[34] K. Yang, T. Koike, H. Ishikawa et al., "Turbulent flux transfer over bare-soil surfaces: characteristics and parameterization," Journal of Applied Meteorology \& Climatology, vol. 47, no. 1, pp. 276-290, 2008.

[35] L. Mahrt, "Flux sampling errors for aircraft and towers," Journal of Atmospheric and Oceanic Technology, vol. 15, no. 2, pp. 416429, 1998.

[36] Q. Zhang, X. Cao, G. Wei, and R. Huang, "Observation and study of land surface parameters over Gobi in typical arid region," Advances in Atmospheric Sciences, vol. 19, no. 1, pp. 120$135,2002$. 
[37] K. E. Taylor, "Summarizing multiple aspects of model performance in a single diagram," Journal of Geophysical Research: Atmospheres, vol. 106, no. 7, pp. 7183-7192, 2001.

[38] J. Kariyeva, W. J. D. van Leeuwen, and C. A. Woodhouse, "Impacts of climate gradients on the vegetation phenology of major land use types in Central Asia (1981-2008)," Frontiers of Earth Science, vol. 6, no. 2, pp. 206-225, 2012.

[39] M. Y. Leclerc and G. W. Thurtell, "Footprint prediction of scalar fluxes using a Markovian analysis," Boundary-Layer Meteorology, vol. 52, no. 3, pp. 247-258, 1990.

[40] H. P. Schmid, "Source areas for scalars and scalar fluxes," Boundary-Layer Meteorology, vol. 67, no. 3, pp. 293-318, 1994.

[41] T. W. Horst and J. C. Weil, "Footprint estimation for scalar flux measurements in the atmospheric surface layer," BoundaryLayer Meteorology, vol. 59, no. 3, pp. 279-296, 1992.

[42] A. Sogachev, M. Y. Leclerc, A. Karipot, G. Zhang, and T. Vesala, "Effect of clearcuts on footprints and flux measurements above a forest canopy," Agricultural \& Forest Meteorology, vol. 133, no. 1-4, pp. 182-196, 2005.

[43] M. Göckede, C. Rebmann, and T. Foken, "A combination of quality assessment tools for eddy covariance measurements with footprint modelling for the characterisation of complex sites," Agricultural and Forest Meteorology, vol. 127, no. 3-4, pp. 175-188, 2004.

[44] M. Göckede, T. Markkanen, M. Mauder, K. Arnold, J.-P. Leps, and T. Foken, "Validation of footprint models using natural tracer measurements from a field experiment," Agricultural and Forest Meteorology, vol. 135, no. 1-4, pp. 314-325, 2005.

[45] C. Rebmann, M. Göckede, T. Foken et al., "Quality analysis applied on eddy covariance measurements at complex forest sites using footprint modelling," Theoretical and Applied Climatology, vol. 80, no. 2-4, pp. 121-141, 2005.

[46] G. Peng, X. Cai, H. Zhang, A. Li, F. Hu, and M. Y. Leclerc, "Heat flux apportionment to heterogeneous surfaces using flux footprint analysis," Advances in Atmospheric Sciences, vol. 25, no. 1, pp. 107-116, 2008.

[47] J. R. Garratt, The Atmospheric Boundary Layer, Cambridge University Press, 1994.

[48] Y. Zhou, X. Sun, Z. Zhu et al., "Surface roughness length dynamic over several different surfaces and its effects on modeling fluxes," Science in China, Series D: Earth Sciences, vol. 49, no. 2, pp. 262-272, 2006.

[49] W. Brutsaert, "Heat and mass transfer to and from surfaces with dense vegetation or similar permeable roughness," BoundaryLayer Meteorology, vol. 16, no. 4, pp. 365-388, 1979.

[50] B. W. Brock, I. C. Willis, and M. J. Sharp, "Measurement and parameterization of aerodynamic roughness length variations at Haut Glacier d'Arolla, Switzerland," Journal of Glaciology, vol. 52, no. 177, pp. 281-297, 2006.

[51] Z. Dong, S. Gao, and D. W. Fryrear, "Drag coefficients, roughness length and zero-plane displacement height as disturbed by artificial standing vegetation," Journal of Arid Environments, vol. 49, no. 3, pp. 485-505, 2001.

[52] N. J. Clifford, A. Robert, and K. S. Richards, "Estimation of flow resistance in gravel-bedded rivers: a physical explanation of the multiplier of roughness length," Earth Surface Processes \& Landforms, vol. 17, no. 2, pp. 111-126, 1992.

[53] H. A. R. De Bruin and C. J. Moore, "Zero-plane displacement and roughness length for tall vegetation, derived from a simple mass conservation hypothesis," Boundary-Layer Meteorology, vol. 31, no. 1, pp. 39-49, 1985.
[54] A. C. Chamberlain, "Roughness length of sea, sand, and snow," Boundary-Layer Meteorology, vol. 25, no. 4, pp. 405-409, 1983.

[55] M. B. Ek, K. E. Mitchell, Y. Lin et al., "Implementation of Noah land surface model advances in the National Centers for Environmental Prediction operational mesoscale Eta model," Journal of Geophysical Research D: Atmospheres, vol. 108, no. 22, pp. 1-16, 2003.

[56] H. Kato, M. Rodell, F. Beyrich et al., "Sensitivity of land surface simulations to model physics, land characteristics, and forcings, at four CEOP sites," Journal of the Meteorological Society of Japan-Series II, vol. 85, pp. 187-204, 2007.

[57] C. K. G. Castillo and K. R. Gurney, "A sensitivity analysis of surface biophysical, carbon, and climate impacts of tropical deforestation rates in CCSM4-CNDV,' Journal of Climate, vol. 26, no. 3, pp. 805-821, 2013.

[58] W. T. Crow and E. F. Wood, "The assimilation of remotely sensed soil brightness temperature imagery into a land surface model using Ensemble Kalman filtering: a case study based on ESTAR measurements during SGP97," Advances in Water Resources, vol. 26, no. 2, pp. 137-149, 2003.

[59] M. Rodell, P. R. Houser, U. Jambor et al., "The global land data assimilation system," Bulletin of the American Meteorological Society, vol. 85, no. 3, pp. 381-394, 2004. 

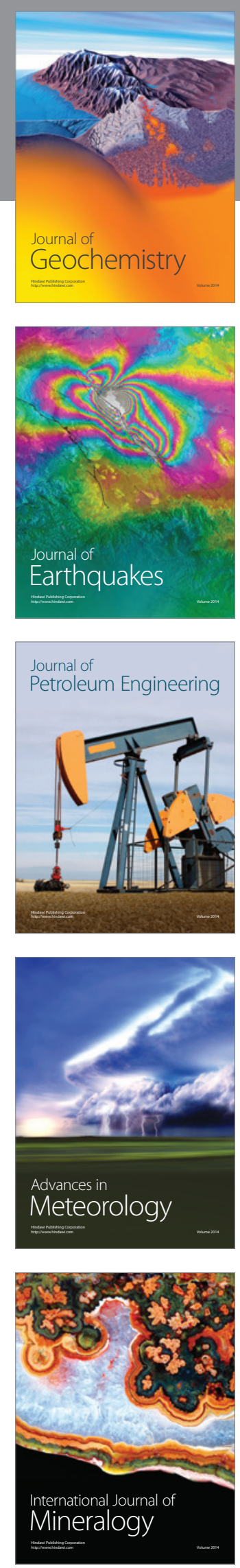
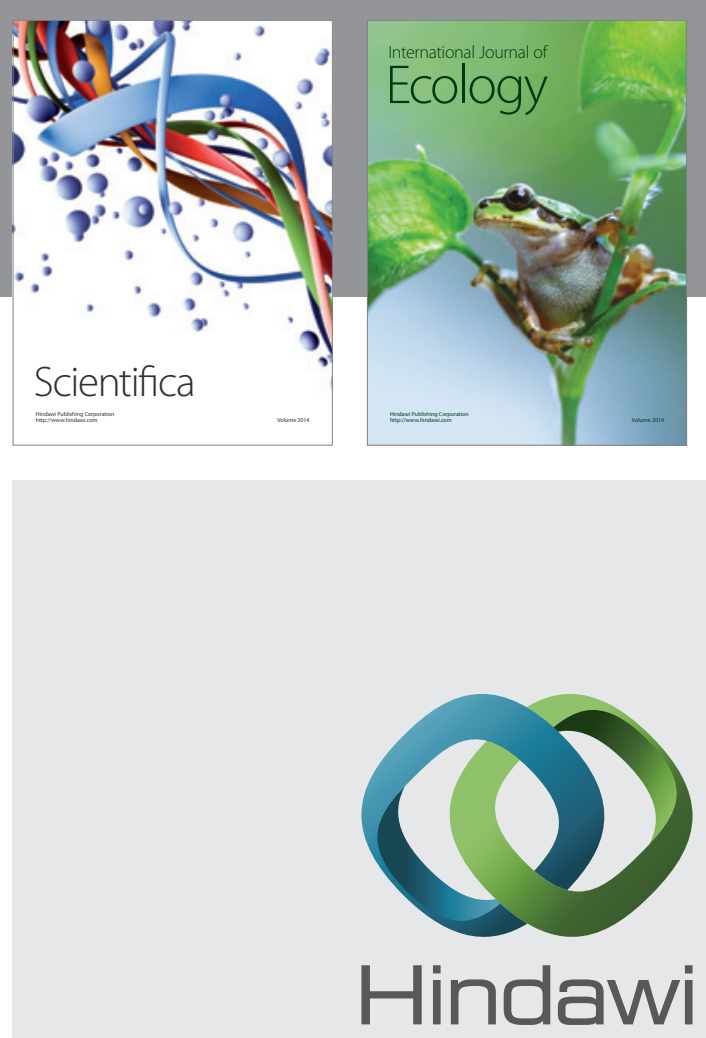

Submit your manuscripts at

http://www.hindawi.com
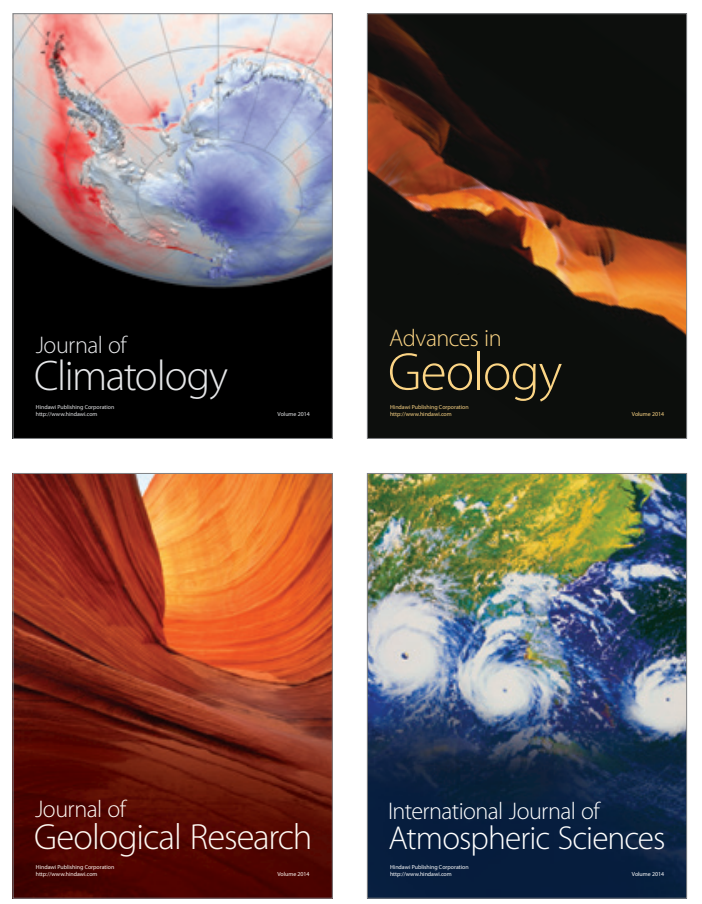

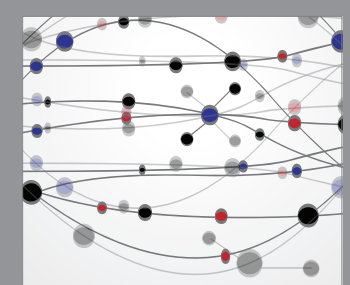

The Scientific

\section{World Journal}
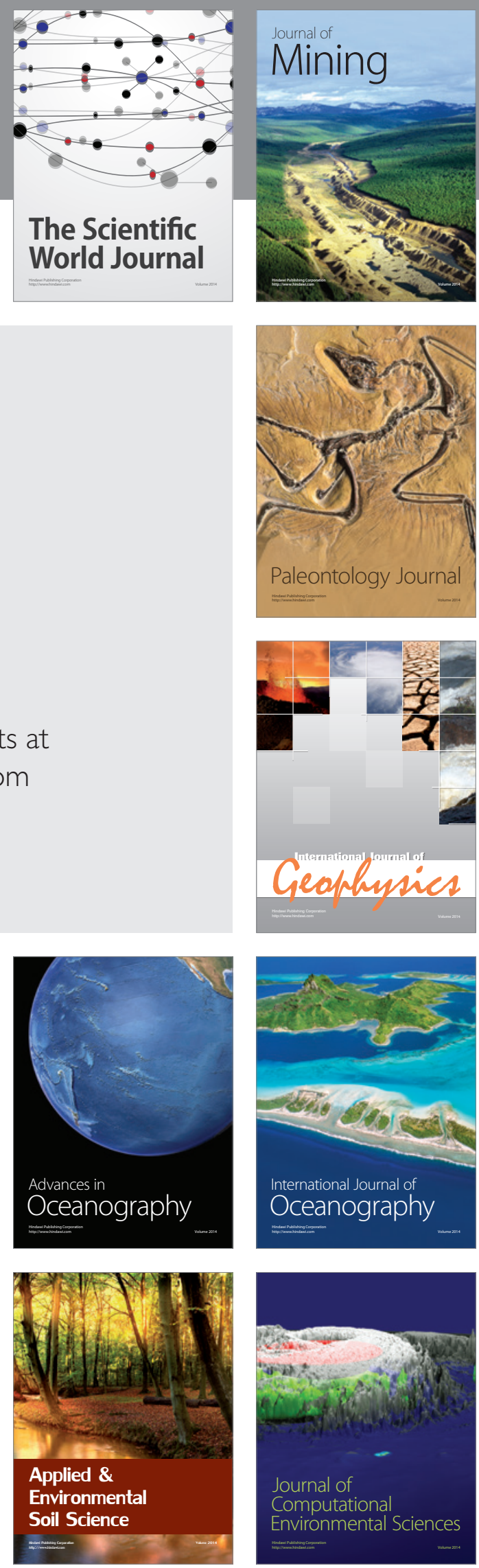